\title{
Destruction of thermal insulation and effectiveness of the thermal energy transfer system
}

\author{
E. R. Bazukova ${ }^{1, *}$, T. O. Politova ${ }^{1}, E . R$. Khaziakhmetova ${ }^{1}, A . A$. Medyakov $^{2}$, and $I$. Kolcunova ${ }^{3}$ \\ ${ }^{1}$ Kazan State Power Engineering University, Kazan, Russia \\ ${ }^{2}$ Volga Region State Technological University, Yoshkar-Ola, Russia \\ ${ }^{3}$ Technical University of Kosice, Kosice, Slovakia
}

\begin{abstract}
The work is devoted to improving the efficiency of the system of thermal energy transportation. The results of determining the thermophysical properties, such as the coefficient of thermal conductivity, water absorption, vapor permeability, the percentage of structural changes in the fibers during heating and exposure to vibration, basalt super thin fiber and other thermal insulation materials are presented. The results of thermal imaging testing control of basalt super-thin fiber mats are presented. The effect of the degree of thermal insulation aging on the increase in the heat flow density is shown.
\end{abstract}

\section{Introduction}

Reducing heat losses during transportation of the coolant is one of the key aspects of improving the efficiency of the thermal energy transportation system. The rise in prices for fuel and energy resources in the context of commercial relationships between energy supplying organizations and consumers makes the problems of more accurate determination of heat and coolant losses urgent.

High-energy-intensive industries, where hightemperature heat-transfer agents (steam) are used in large volumes, have a high potential for energy saving, which is not fully realized.

In many ways, a high level of transport losses of thermal energy is caused by the long-term operation of pipelines in abnormal conditions [1-2].

The effectiveness of the coolant transportation system is influenced by a combination of such factors as the change in the operating mode of the system, as well as the change in the thermophysical properties of the insulation during operation [3-4].

The actual state of thermal insulation, especially in certain areas, may differ significantly from the initial one provided for by the project [5-9].

The durability of thermal insulation depends on the temperature of the insulated surface. So the use of hightemperature coolants (steam) can lead to thermal destruction of thermal insulation. It is known that the materials used in Russia can lead to an increase in the coefficient of thermal conductivity by $20-30 \%$ for the first time already 5 years of operation. For example, manufacturers guarantee that polyurethane foam operates at a temperature of $150^{\circ} \mathrm{C}$. However, in fact, at a temperature of $120^{\circ} \mathrm{C}$, its destruction occurs [10-13].
In connection with the foregoing, an important criterion in the selection of thermal insulation materials is an indicator of the durability of thermal insulation properties, as well as the conservation of the design thermophysical properties of an insulating material throughout the entire service life.

\section{Determination of thermal properties of thermal insulation materials}

The results of the comparison of various heat-insulating materials with one-sided heating, as well as under vibration exposure are presented in table 1. According to the presented results, basalt super-thin fiber is subject to the least structural changes [14].

Determining the sintering temperature of basalt super-thin fiber revealed maximum temperature indexes for densities of $30 \mathrm{~kg} / \mathrm{m}^{3} ; 40 \mathrm{~kg} / \mathrm{m}^{3} ; 60 \mathrm{~kg} / \mathrm{m}^{3}$ (Figure 1). Average index is $1144{ }^{\circ} \mathrm{C}$.

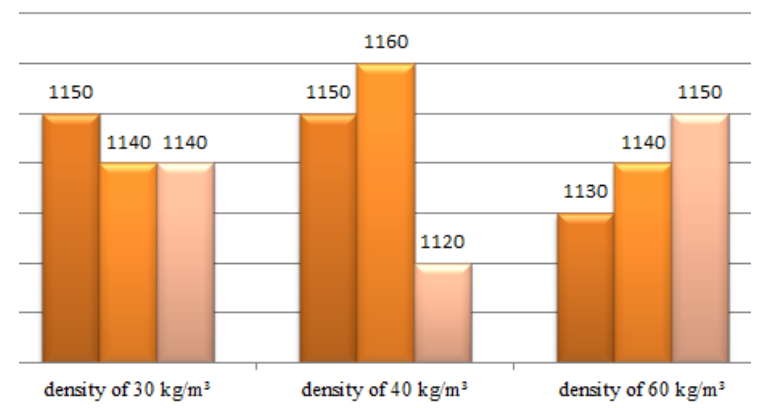

Fig. 1. BSTF sintering temperature.

The determination of such thermal insulation properties as water absorption (see Table 2) and vapor permeability was also conducted (Figure 2).

* Corresponding author: ell17@mail.ru 
Table 1. The percentage of structural changes in various fibers with one-sided heating for three hours with vibration frequency $v$ $=50 \mathrm{~Hz}$ and amplitude $\mathrm{A}=1 \mathrm{~mm}$.

\begin{tabular}{|c|c|c|c|c|c|c|}
\hline Fibername & \begin{tabular}{c} 
Initial thickness of \\
the test sample, \\
\cline { 3 - 7 }
\end{tabular} & 400 & 600 & 700 & 800 & 900 \\
\hline BTF & 40 & 2.0 & 2.0 & 5.0 & 9.0 & 12.0 \\
\hline Fiberglass & 40 & 95 & 100 & 100 & 100 & 100 \\
\hline BSTF & 40 & 0.01 & 0.15 & 0.23 & 0.03 & 0.35 \\
\hline Mineral fiber & 40 & 75 & 95 & 100 & 100 & 100 \\
\hline Slag fiber & 40 & 100 & 100 & 100 & 100 & 100 \\
\hline
\end{tabular}

Table 2. Water absorption of various heat-insulating materials.

\begin{tabular}{|c|c|c|c|c|c|c|}
\hline \multirow{2}{*}{ Water absorption, \% } & $\begin{array}{c}\text { Polyethylene } \\
\text { foam }\end{array}$ & $\begin{array}{c}\text { Reinforced } \\
\text { foamconcrete }\end{array}$ & $\begin{array}{c}\text { Improved reinforced } \\
\text { foam concrete }\end{array}$ & $\begin{array}{c}\text { Polyurethane } \\
\text { foam }\end{array}$ & $\begin{array}{c}\text { Phenolic } \\
\text { porous } \\
\text { plastics }\end{array}$ & BSTF \\
\cline { 2 - 7 } & 1 & 20 & 15 & 10 & 40 & 1 \\
\hline
\end{tabular}

Table 3. Thermal conductivity of basalt fibers of different density depending on temperature.

\begin{tabular}{|c|c|c|c|c|c|c|}
\hline \multirow{3}{*}{$\begin{array}{c}\text { Average } \\
\text { temperature, }{ }^{\circ} \mathrm{C}\end{array}$} & \multicolumn{6}{|c|}{ Fiber thermal conductivity, $\mathrm{W} /\left(\mathrm{m}^{\circ} \mathrm{C}\right)$, by density $\mathrm{kg} / \mathrm{m}^{3}$} \\
\hline & \multicolumn{2}{|c|}{60} & \multicolumn{2}{|c|}{80} & \multicolumn{2}{|c|}{100} \\
\hline & BTF & BSTF & BTF & BSTF & BTF & BSTF \\
\hline 50 & 0.06 & 0.0475 & 0.057 & 0.044 & 0.054 & 0.046 \\
\hline 100 & 0.072 & 0.0495 & 0.068 & 0.049 & 0.062 & 0.051 \\
\hline 150 & 0.085 & 0.055 & 0.081 & 0.055 & 0.073 & 0.056 \\
\hline 200 & 0.105 & 0.062 & 0.097 & 0.0605 & 0.086 & 0.061 \\
\hline 250 & 0.129 & 0.0695 & 0.117 & 0.0665 & 0.091 & 0.0765 \\
\hline 300 & 0.166 & 0.077 & 0.141 & 0.072 & 0.118 & 0.0715 \\
\hline
\end{tabular}

Thus, when choosing a heat-insulating material, an important indicator is not only a low coefficient of thermal conductivity (see table 3), but also such properties as water absorption, vapor permeability, sintering temperature, the amount of structural changes during heating, which allow to maintain the thermal properties stated in the design from the operating conditions of pipelines for a long time.

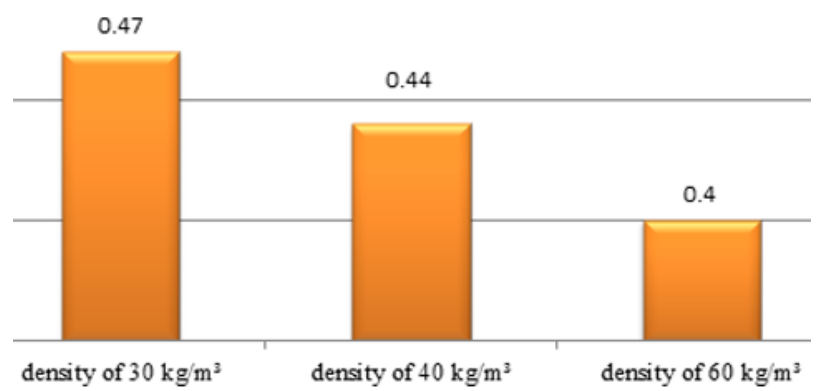

Fig. 2. Determination of BSTF vapor permeability, $\mathrm{mg} /(\mathrm{m} \cdot \mathrm{h} \cdot \mathrm{Pa})$.

\section{Results}

According to the results of a seven-day test of BSTF mats $(60 \mathrm{~mm}$ thick, density 70$)$ at the Zelenodolsk plywood factory (gas supply pipeline) the following indexes were achieved: The temperature at the surface of the gas supply pipeline is $235^{\circ} \mathrm{C}$. The temperature on the surface of the material is $35^{\circ} \mathrm{C}$. The results of thermal imaging control are presented in Figure 3.

According to the methodology described in Building codes and regulations 41-03-2003 "Thermal insulation of equipment and pipelines" (updated version of Set of rules 61.13330.2012) [15-16], the specific heat losses of the steam pipeline above-ground gasket d-159 $\mathrm{mm}$ were calculated, through which steam with temperature of 194 ${ }^{\circ} \mathrm{C}$, thermal insulation basalt + polyurethane foam (the initial state of thermal insulation and with destruction was taken into account). It was also considered the option of using as insulating material BSTF. The calculation results are presented in the diagram (Figure 4). 


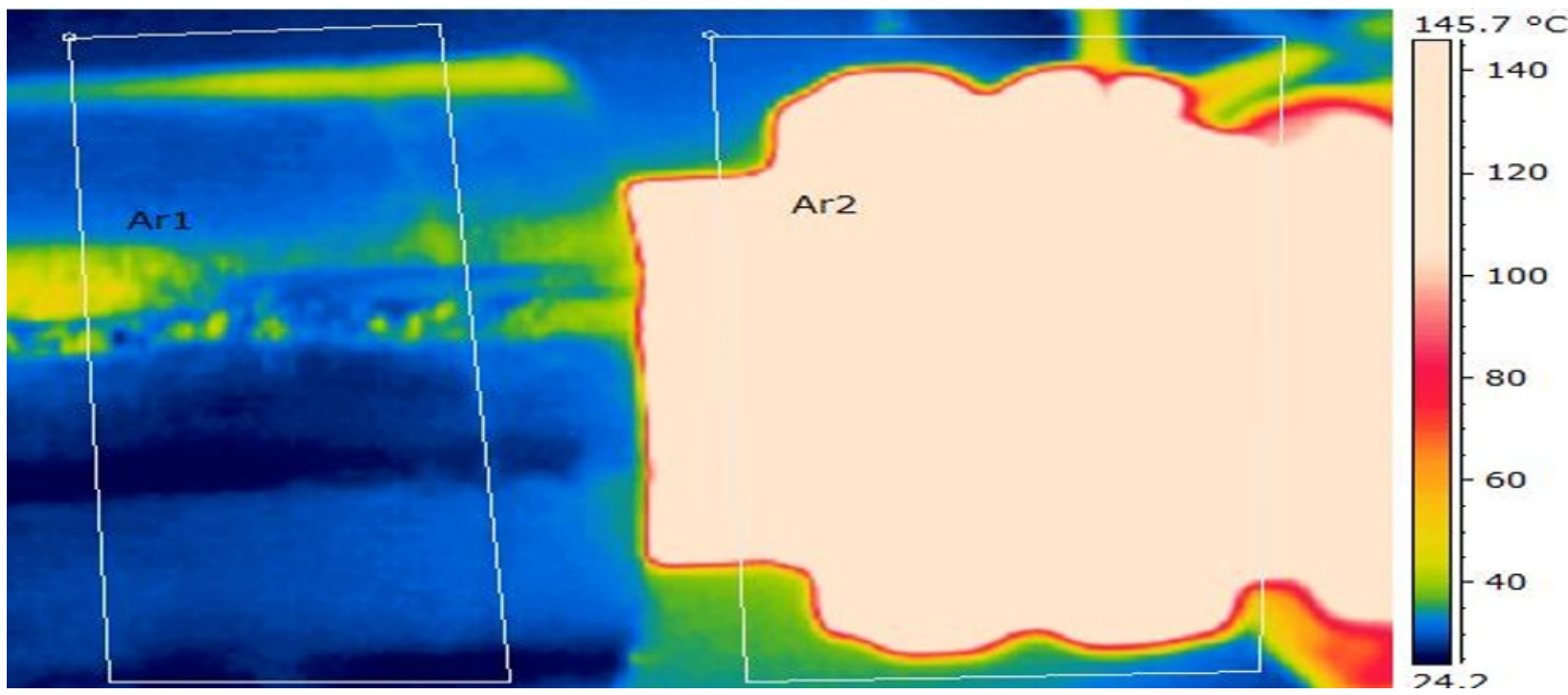

Fig. 3. The results of the thermal imaging control test of BSTF mats: Ar 1 - installation zone with cylinders, Ar 2 - installation zone without cylinders.

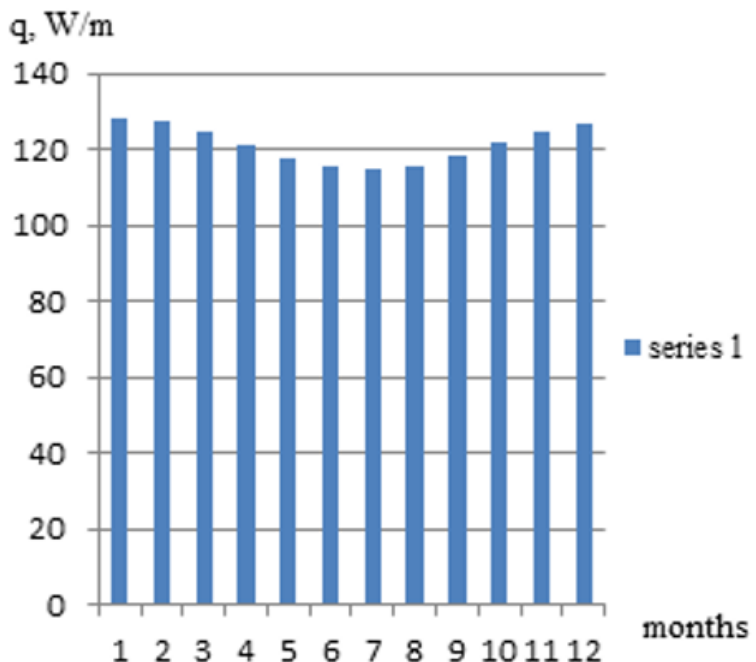

a) $\mathrm{q}, \mathrm{W} / \mathrm{m}$

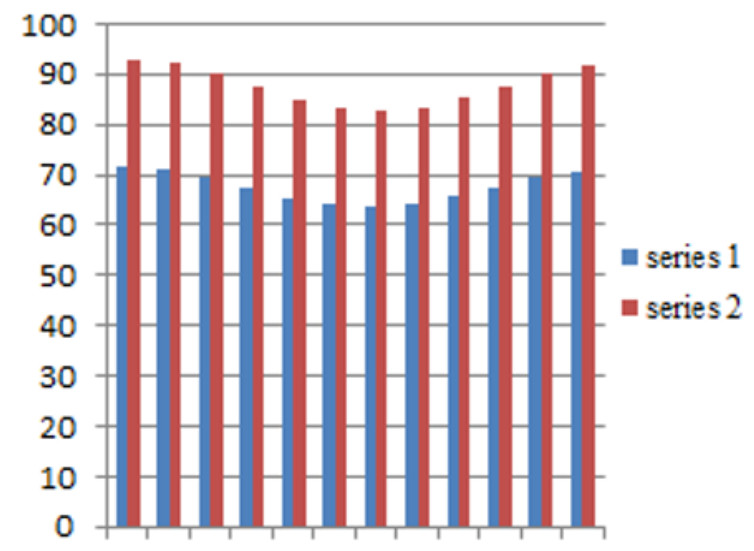

$\begin{array}{lllllllllll}1 & 2 & 3 & 4 & 5 & 6 & 7 & 8 & 9 & 1011 & 12 \\ \text { months }\end{array}$

b)

Fig. 4. The results of the calculation of the specific heat losses of the steam line d-159 mm. a) thermal insulation BSTF, b) thermal insulation basalt + PU foam, series 1 - specific heat losses without taking into account the temperature destruction of PU foam insulation, series 2 - specific heat losses with an increase in the coefficient of thermal conductivity due to temperature destruction on $20 \%$.

\section{Conclusions}

The results indicate the need to take into account the actual operating conditions when assessing heat losses.

Also, when designing thermal insulation, it is necessary to take into account the amount of structural changes, sintering temperature, water absorption and vapor permeability of heat-insulating materials, which affects the amount of heat losses during long-term operation in various working conditions.

\section{References}

[1] Yu.S. Tsygankova Express-assessment of heat losses in heating networks News of higher educational institutions. Problems of energy 5-6, 23-28 (2014)

[2] E.V. Izmailova, T.O. Politova, V.V. Serov, Development of methods of detection of pipelines corrosion defeat by computer modeling 2nd international conference on industrial engineering, applications and manufacturing 10.1109/ICIEAM.2016.7911605 (2016)

[3] R. Zwierzchowski, O. Niemyjski, Influence of different operating conditions of a district heating and 
cooling system on heat transportation losses of a district heating network Conf. ser.: Materials science and engineering 471 042019, (2019)

[4] E.R. Saifullin, Y.V. Vankov, E.R. Bazukova, A.V. Maryashev, Evaluation of heat transporting losses due to ghanges of insulation properties during operation Journal of physics: conf. ser. 9, Low-temperature plasma during the deposition of functional coatings vol. Scientific technical conference on low temperature plasma during the deposition of functional coatings 1058 012061, (2018)

[5] E.R. Bazukova, and Yu.V. Vankov Heat losses with deterioration of insulation properties during operation Don engineering bulletin 3 3249, (2015)

[6] Yu.V. Vankov, E.R. Bazukova, S.I. Islamova, A.V. Busarov, Assessment of heat transport losses during insulation aging Innovative, information and communication technologies 1, 572-576 (2017)

[7] I.A. Zakirova, and N.D. Chichirova, The improving effectiveness thermal insulation of heating systems with thin-film covering using International journal of civil engineering and technology (IJCIET) 10, 1142-1146 (2019)

[8] T.N. Nemova, Yu.A. Lezhneva, N.A. Tsvetkov, Ye.G. Alekseeva, The effect of changes in thermal conductivity of insulating materials on the heat losses of main pipelines Tomsk state architecturalbuilding univ. bulletin 5, 151-160 (2016)

[9] Yu.V. Vankov, E.R. Bazukova, A.S. Gavrilov, Assessment of transport losses of heat at change of properties of thermal isolation IOP conf. series: earth and environmental science 012127, 288 (2019)

[10] V.P. Yartsev, A.A. Mamontov, S.A. Mamontov, Operational properties and durability of thermal insulation materials (mineral wool and polystyrene foam) Roofing and insulating materials 1, 811 (2013)

[11] O.V. Smorodova, Instrumental assessment of the aging dynamics of mineral wool thermal insulation Innovation science 7-8, 90-92 (2016)

[12] O.V. Smorodova, Dynamics of heat-shielding properties of mineral wool thermal insulation with the time of operation Scientific-practical electronic journal Alley of Science 9, 367-370 (2017)

[13] A.G. Dementiev, Assesment of the service life of polyurethane foam for thermal insulation Polyurethane foam 2, 38-41 (2000)

[14] https://bos-pro.ru

[15] Set of rules: SR 41-103-2000 Design of thermal insulation of equipment and pipelines 2012 regulatory and technical material (Moscow: Ministry of Regional Development of Russia)

[16] B.M. Shoyhet, Desing of thermal insulation ofthermal networks heat pipelines Energysaving 1, 66-67 (2015) 